\title{
Patterned Asymmetry in Tooth Emergence Timing
}

\author{
STANLEY M. GARN and B. HOLLY SMITH
}

Center for Human Growth \& Development, The University of Michigan, Ann Arbor, Michigan 48109

\section{J Dent Res (59)9:1526-1527, September 1980}

Although attention has been directed to asymmetries in mesiodistal and buccolingual crown dimensions, beginning with Ballard (Angle Ortho $68: 67,1944)$, there are also left-right differences in tooth emergence timing that are of investigative interest and possible clinical concern. Since isomeres may emerge several years apart in some cases, there is a need to ascertain the extent to which emergence asymmetry is patterned, the degree of correspondence in asymmetry between the jaws, and the possible relationship between permanent tooth emergence order and the degree of emergence timing asymmetry.

To accomplish this we have made use of serial longitudinal tooth emergence data on Michigan boys and girls (Garn and Smith, $J$ Dent Res, in press, 1980), calculating emergence asymmetry both as left-right correlations $(r)$ using sex-specific $\mathrm{Z}$-scores for emergence age and as R.M.S. asymmetry $\left(\sigma_{\mathrm{d}}\right)$ using absolute age difference in the emergence of antimeres. The first of these two measures corrects the differences in emergence timing variability, and the second does not. For means of comparison we ranked the coefficient of alienation $\left(1-r^{2}\right)$ and R.M.S. asymmetry $\left(\sigma_{d}\right)$ from lowest to highest, for seven teeth within each jaw. Finally, we ranked permanent tooth emergence order using the male order of means as shown in the table.

Where values of $r, 1-r^{2}$ and $\left(\sigma_{\mathrm{d}}\right)$ asymmetry are given to two decimal places, the rankings of left-right asymmetry are somewhat different for the two measures within a jaw. They are, however, very similar between the jaws, as indicated by a rank order correlation (rho) for upper and lower

Received for publication November 19, 1979 Accepted for publication February 20, 1980 antimere asymmetry of 0.78 for $1-r^{2}$ and 0.71 for R.M.S. asymmetry $\left(\sigma_{\mathrm{d}}\right)$. There is, therefore, good inter-jaw correspondence in the pattern of emergence asymmetry by both measures. Interestingly, tooth size asymmetry is found to follow the same trend. When these Michigan subjects are ranked according to R.M.S. asymmetry of buccolingual crown diameters, as reported by Garn and Bailey ( $J$ Dent Res 56:1422, 1977), upper and lower isomers similarly show a rank order correlation of 0.89 .

When emergence timing asymmetry rankings are compared with the rankings of emergence order for the same teeth, using either left-right correlations or the coefficient of alienation, rank order correlations (tho) are negative both for the maxilla $(-0.57)$ and the mandible $(-0.93)$. However, when left-right asymmetry in emergence timing is expressed as R.M.S. asymmetry $\left(\sigma_{\mathrm{d}}\right)$, the corresponding correlations are 0.11 and 0.18 . Left-right asymmetry in emergence timing, as expressed by left-right correlations, therefore, are inversely related to the sequence or order of emergence. This, however, is not the case when absolute emergence asymmetry measures are employed.

A much larger sample of longitudinally collected emergence data is necessary to confirm these findings with a target $\mathrm{N}$ of 600 or more. Nevertheless, these findings do suggest that left-right tooth emergence asymmetry, like crown-size asymmetry, is strongly patterned with marked similarities between the jaws. The further suggestion of an inverse relationship between left-right asymmetry in emergence timing and left-right asymmetry in the order of emergence presents a new developmental interrelationship for consideration. The existence of systematic relationships of emergence asymmetry between the jaws and of other measures of dental development points the way to further studies on patterned emergence asymmetry and its implications to normal and abnormal craniofacial growth. 
TABLE

EMERGENCE TIMING ASYMMETRY COEFFICIENTS AND RANKINGS

\begin{tabular}{|c|c|c|c|c|c|c|c|}
\hline \multirow[b]{2}{*}{ Tooth } & \multirow[b]{2}{*}{$\mathrm{N}$} & \multirow{2}{*}{$\begin{array}{l}\text { Left-right } \\
\text { correlation (r) }\end{array}$} & \multirow{2}{*}{$\begin{array}{c}\text { Alienation } \\
\left(1-r^{2}\right)\end{array}$} & \multirow[b]{2}{*}{$\sigma_{\mathrm{d}}^{*}$} & \multicolumn{3}{|c|}{ Rankings } \\
\hline & & & & & $1-r^{2}$ & $\sigma_{\mathrm{d}}$ & Emergence \\
\hline \multicolumn{8}{|c|}{ Maxillary } \\
\hline I1 & 143 & .81 & .34 & .47 & 7 & 4 & 2 \\
\hline 12 & 144 & .85 & .28 & .49 & 6 & 5 & 3 \\
\hline $\mathrm{C}$ & 104 & .85 & .28 & .55 & 5 & 6 & 6 \\
\hline P1 & 127 & .90 & .19 & .46 & 2 & 3 & 4 \\
\hline $\mathrm{P} 2$ & 92 & .88 & .23 & .60 & 3 & 7 & 5 \\
\hline M1 & 140 & .86 & .26 & .39 & 4 & 2 & 1 \\
\hline $\mathrm{M} 2$ & 77 & .95 & .10 & .37 & 1 & 1 & 7 \\
\hline \multicolumn{8}{|c|}{ Mandibular } \\
\hline I1 & 129 & .84 & .29 & .37 & 6 & 2 & 1 \\
\hline 12 & 145 & .87 & .24 & .40 & 5 & 3 & 3 \\
\hline $\mathrm{C}$ & 139 & .87 & .24 & .49 & 4 & 6 & 4 \\
\hline P1 & 126 & .91 & .17 & .44 & 2 & 5 & 5 \\
\hline P2 & 93 & .91 & .17 & .51 & 3 & 7 & 6 \\
\hline M1 & 133 & .80 & .36 & .42 & 7 & 4 & 2 \\
\hline M2 & 92 & .95 & .10 & .33 & 1 & 1 & 7 \\
\hline
\end{tabular}

*RMS asymmetry expressed in years.

\section{ANNOUNCEMENT}

As of June 30,1980 , no more annotations were accepted for the JOURNAL OF DENTAL RESEARCH. All annotations currently in progress will be published. All other submissions to the JOURNAL are now being processed as regular papers. 